\title{
Comparison of the bromodeoxyuridine-mediated sensitization effects between low-LET and high-LET ionizing radiation on DNA double-strand breaks
}

\author{
YOSHIHIRO FUJII $^{1,2}$, MATTHEW D. GENET ${ }^{3}$, ERICA J. ROYBAL ${ }^{3}$, NOBUO KUBOTA ${ }^{1}$, \\ RYUICHI OKAYASU ${ }^{4}$, KIYOSHI MIYAGAWA ${ }^{2}$, AKIRA FUJIMORI ${ }^{4}$ and TAKAMITSU A. KATO ${ }^{3}$ \\ ${ }^{1}$ Department of Radiological Sciences, Ibaraki Prefectural University of Health Sciences, Inashiki, Ibaraki 300-0394; \\ ${ }^{2}$ The University of Tokyo, Graduate School of Medicine, Bunkyo, Tokyo 113-0033, Japan; \\ ${ }^{3}$ Department of Environmental and Radiological Health Sciences, Colorado State University, \\ Fort Collins, CO 80523, USA; ${ }^{4}$ National Institute of Radiological Sciences, Research Center \\ for Charged Particle Therapy, International Open Laboratory, Anagawa Inage, Chiba 263-8555, Japan
}

Received November 13, 2012; Accepted December 17, 2012

DOI: $10.3892 /$ or.2013.2354

\begin{abstract}
The incorporation of halogenated pyrmidines such as bromo- and iodo-deoxyuridines (BrdU, IdU) into DNA as thymidine analogs enhances cellular radiosensitivity when high-linear energy transfer (LET) radiation is not used. Although it is known that high-LET ionizing radiation confers fewer biological effects resulting from halogenated pyrimidine incorporation, the exact mechanisms of reduced radiosensitivity with high-LET radiation are not clear. We investigated the radiosensitization effects of halogenated pyrimidines with high-LET radiation using accelerated carbon and iron ions. Cells synchronized into the $\mathrm{G}_{1}$ phase after unifilar ( 1 cell cycle) and bifilar ( 2 cell cycles) substitution with $10 \mu \mathrm{M}$ BrdU were exposed to various degrees of LET with heavy ions and X-rays. We then carried out a colony formation assay to measure cell survival. The $\gamma$-H2AX focus formation assay provided a measure of DNA double-strand break (DSB) formation and repair kinetics. Chromosomal aberration formations for the first post-irradiation metaphase were also scored. For both low-LET X-rays and carbon ions $(13 \mathrm{keV} / \mu \mathrm{m})$, BrdU incorporation led to impaired DNA repair kinetics, a larger initial number of DNA DSBs more frequent chromosomal aberrations at the first post-irradiated metaphase, and increased radiosensitivity for cell lethality. The enhancement ratio was higher after bifilar substitution. In contrast, no such synergistic enhancements were observed after high-LET irradiation with carbon and iron ions (70 and $200 \mathrm{keV} / \mu \mathrm{m}$, respectively), even after bifilar substitution. Our results suggest that BrdU substi-
\end{abstract}

Correspondence to: Dr Takamitsu A. Kato, Department of Environmental and Radiological Health Sciences, Colorado State University, 1618 Campus Delivery, Fort Collins, CO 80523, USA

E-mail: tkato@rams.colostate.edu

Key words: bromodeoxyuridine, linear energy transfer, doublestrand break tution did not modify the number and quality of DNA DSBs produced by high-LET radiation. The incorporation of halogenated pyrimidines may produce more complex/clustered DNA damage along with radicals formed by low-LET ionizing radiation. In contrast, the severity of damage produced by high-LET radiation may undermine the effects of BrdU and account for the observed minimal radiosensitization effects.

\section{Introduction}

Halogenated pyrimidines are well known as classic radiosensitizers for low-linear energy transfer (LET) radiation such as $\mathrm{X}$-rays and $\gamma$-rays (1-4). They also have strong sensitization effects for visible and ultraviolet light (5-7). The mechanisms of bromodeoxyuridine (BrdU)-mediated radiosensitization have been explained elsewhere (8-12). Simply put, singlestrand break formation from BrdU-mediated radicals results in the formation of lethal DNA double-strand breaks (DSBs). Since sensitization can be partially reduced by adding radical scavengers such as acetone, various reports suggest that BrdU either produces lethal DSBs or fixes potentially lethal damage (PLD) to enhance cell killing (13-16).

High-LET radiation has a strong effect on cell killing when compared to low-LET radiation. Namely, it achieves a higher relative biological effectiveness (RBE) than low-LET radiation (17-20) by producing dense ionization and causing complex, clustered DNA damage (21-24). However, the complex clustered damage produced by high-LET radiation is not fully understood (21). Radiosensitizers are typically less effective when using high-LET radiation when compared with low-LET radiation $(25,26)$.

Reports have indicated that the incorporation of halogenated pyrimidines not only increases the magnitude of radiation-induced DNA damage, but also suppresses DNA damage repair $(2,9,16)$. High-LET radiation produces 'clustered damage', a type of DNA damage which is also difficult to repair $(2,9,16)$. LET-dependent sensitization of halogenated pyrimidines is reported in cellular lethality (25). As LET 
increases, increased clustered DNA damage is formed. At LET $>100 \mathrm{keV} / \mu \mathrm{m}$, the RBE declines as LET increases $(27,28)$.

We hypothesized that the mechanism of BrdU-induced hypersensitivity to ionizing radiation is based on the quality of DNA DSBs. We examined the effects of combinations of high-LET heavy ions and unifilar and bifilar BrdU substitution in Chinese hamster ovary $(\mathrm{CHO})$ cells to better understand the BrdU dependency. In this study, we revealed that BrdU substitution followed by low-LET radiation altered DNA damages into more complex damages similar to those observed after high-LET radiation exposure only, while no additional effects on cellular lethality, chromosomal aberrations and DNA DSB formation and repair were observed following high-LET radiation with BrdU.

\section{Materials and methods}

Cell lines and culture. Chinese Hamster ovary (CHO10B2) cells (wild-type) were kindly supplied by Dr Joel Bedford of Colorado State University (Fort Collins, CO, USA). Cells were grown in $\alpha$ MEM (Invitrogen, Carlsbad, CA, USA) supplemented with $10 \%$ heat-inactivated $\left(56^{\circ} \mathrm{C}\right.$ for $\left.30 \mathrm{~min}\right)$ fetal bovine serum (FBS, Sigma, St. Louis, MO, USA) and 1\% antibiotics and antimycotics (Invitrogen) in a humidified 5\% $\mathrm{CO}_{2}$ atmosphere at $37^{\circ} \mathrm{C}$. Cell doubling time was $\sim 12 \mathrm{~h}$.

Irradiation and drug treatment. Cells were cultured in a moderately toxic concentration of $\operatorname{BrdU}(10 \mu \mathrm{M}$, Sigma, St. Louis, MO, USA) for our experiments. Log phase cells were cultured in $10 \mu \mathrm{M} \mathrm{BrdU}$ for 10 or $20 \mathrm{~h}$ before synchronization to achieve unifilar (>95\%) or bifilar ( 95\%) substitution, respectively. The substitution of BrdU was confirmed by immunocytochemistry against the BrdU antibody (BD, Franklin Lakes, NJ, USA) for unifilar and fluorescence plus Giemsa (FPG) differential staining on metaphase chromosomes for bifilar (29). Cell cycle synchronization was achieved by the mitotic shake-off method (30). Two hours after shake-off, $>95 \%$ of cells were synchronized in the $G_{1}$ phase before they were exposed to ionizing radiation. Cell synchronization was confirmed by flow cytometry. The Titan X-ray irradiator $(200 \mathrm{kVp}, 20 \mathrm{~mA}$, 0.5-mm Al and 0.5-mm Cu filters; Shimadzu, Japan) yields an $\mathrm{X}$-ray dose of $\sim 1 \mathrm{~Gy} / \mathrm{min}$ at room temperature. For heavy ion exposure, accelerated ions were irradiated using the Heavy Ion Medical Accelerator in Chiba (HIMAC) at room temperature. Radiation exposure was carried out in a dark environment to prevent cellular toxicity from room light. Dosimetry and beam quality tests for heavy ions were carried out and confirmed by operators of Accelerator Engineering Corp. (Chiba, Japan) (31-34).

Chromosomal aberration assay. To achieve first metaphase arrest, post-irradiated cells were treated with $0.1 \mu \mathrm{g} / \mathrm{ml}$ Colcemid (Sigma) 10-16 h after irradiation. The cells were treated with $75 \mathrm{mM} \mathrm{KCl}$ for $15 \mathrm{~min}$ at $37^{\circ} \mathrm{C}$. After hypotonic treatment, the cells were fixed with fixative [methanol:acetic acid solution (3:1)] three times and were dropped onto slides. The samples were stained with filtered $10 \%$ (v/v) Giemsa solution in Gurr solution (Invitrogen). At least 30 metaphase cells were scored in at least three separate experiments. Chromosomal aberrations were scored as dicentric, fragment, ring, and interstitial and terminal deletion and pooled as total chromosomal aberrations per cell.

Colony formation assay. Cells were trypsinized and plated into P-60 cell culture dishes immediately after the ionizing radiation exposure. Approximately one week later, cells were fixed with $100 \%$ ethanol and stained with crystal violet for colony counting. Colonies containing $>50$ cells were counted as survivors. Plating efficiency was $\sim 75 \%$ for the control and $70 \%$ for both unifilar and bifilar cells. RBE was calculated from doses required to achieve $10 \%$ survival fraction, and the sensitization enhancement ratio (SER) was calculated from the doses required to achieve $37 \%$ cell survival.

$\gamma-H 2 A X$ formation assay. Synchronized cells were grown on chamber slides for $2 \mathrm{~h}$. After irradiation of $1 \mathrm{~Gy}$ and various incubation times $(1,2$, or $3 \mathrm{~h}$ post-irradiation), the cells were fixed and stained as previously described $(35,36)$. Cellular imaging was accomplished using an Olympus FV300 fluorescence confocal microscope equipped with an Olympus Fluoview three dimensional image analysis system (Olympus, Tokyo, Japan). The foci were scored in at least 50 cells per data point. Three to four independent experiments were carried out.

Statistical analysis. Statistical comparison of mean values was performed using a t-test. Differences with a P-value of $<0.05$ were considered to indicate a statistically significant result. Error bars indicate standard error of the means. Confidence interval values were calculated by Prism $5^{\mathrm{TM}}$ software (GraphPad, La Jolla, CA, USA).

\section{Results}

Comparison of the BrdU substitution-induced radiosensitization effect with $X$-rays and heavy ions in a colony formation assay. For X-rays and carbon ions with LET of $13 \mathrm{keV} / \mu \mathrm{m}$, BrdU-incorporated cells were more sensitive to ionizing radiation when compared with the BrdU-negative controls (Fig. 1A and B). Both the initial shoulder and slope of the survival curves were affected by BrdU incorporation. The sensitization effect of BrdU bifilar substituted cells was stronger than unifilar incorporation. In contrast, for higher LET using heavy ions such as carbon ions at LET of $70 \mathrm{keV} / \mu \mathrm{m}$ or iron ions at LET of $200 \mathrm{keV} / \mu \mathrm{m}$, BrdU substitution did not induce synergistic sensitization with ionizing radiation (Fig. $1 C$ and D). The $\mathrm{D}_{10}$ value, the dose which resulted in $10 \%$ cell survival and the $D_{37}$, value, the dose which resulted in $37 \%$ cell survival, decreased depending on the level of BrdU incorporation (Table I). For example, the $\mathrm{D}_{10}$ value of 5.4 for $\mathrm{X}$-irradiated unlabeled cells was reduced to 3.6 in bifilarly labeled cells, and that of 4.9 for $13 \mathrm{keV} / \mu \mathrm{m}$ LET carbon ion-exposed unlabeled cells was reduced to 3.4 in bifilarly labeled cells. For high-LET radiation, the change in $\mathrm{D}_{10}$ value of LET $70 \mathrm{keV} / \mu \mathrm{m}$ carbon ions was from 2.7 to 2.3 , and that of LET $200 \mathrm{keV} / \mu \mathrm{m}$ iron ions was from 2.4 to 2.1 for unlabeled to bifilar BrdU substitution. Differences between sets of $\mathrm{D}_{10}$ values were statistically significant. On the other hand, for the $\mathrm{D}_{37}$ values of unlabeled and bifilar BrdU substitution for high-LET carbon and iron ions, differences between them were regarded as statistically not significant. 

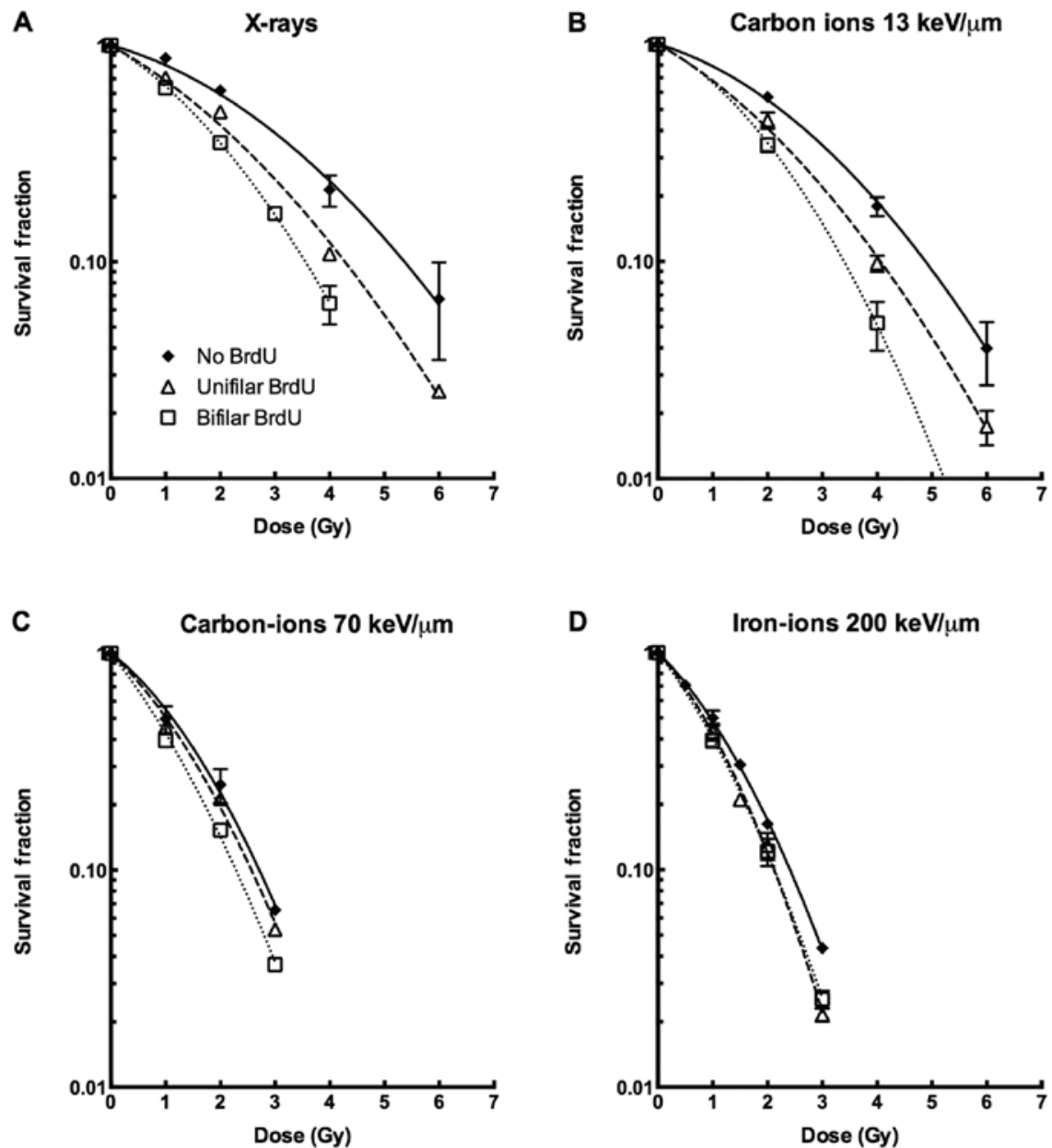

Figure 1. Clonogenic survival curves for different radiation qualities and BrdU incorporation. (A) X-rays, (B) LET $13 \mathrm{keV} / \mu \mathrm{m}$ carbon ions, (C) LET $70 \mathrm{keV} / \mu \mathrm{m}$ carbon ions, (D) LET $200 \mathrm{keV} / \mu \mathrm{m}$ iron ions. $\bullet$, No BrdU substitution; $\Delta$, unifilar substitution; $\square$, bifilar substitution. Three to five independent experiments were carried out. Error bars indicate standard error of the means. Error bars smaller than symbols are not visible. Curves were drawn by GraphPad Prism 5 with linear quadratic regression.

Table I. Relationship between the $\mathrm{D}_{10}$ and $\mathrm{D}_{37}$ values and BrdU incorporation for different radiation qualities.

\begin{tabular}{lcccc}
\hline Radiation & $\mathrm{D}_{10}, \mathrm{D}_{37}$ & No BrdU & Unifilar BrdU & Bifilar BrdU \\
\hline X-ray & $\mathrm{D}_{10}$ & $5.4(4.89-5.86)$ & $4.3(4.08-4.45)$ & $3.6(3.39-3.72)$ \\
& $\mathrm{D}_{37}$ & $3.1(2.49-3.58)$ & $2.3(2.00-2.51)$ & $1.9(1.68-2.15)$ \\
Carbon ions & $\mathrm{D}_{10}$ & $4.9(4.46-5.20)$ & $4.1(3.77-4.28)$ & $3.4(2.98-3.66)$ \\
$13 \mathrm{keV} / \mu \mathrm{m}$ & $\mathrm{D}_{37}$ & $2.9(2.16-3.33)$ & $2.2(1.80-2.50)$ & $1.9(1.48-2.30)$ \\
Carbon ions & $\mathrm{D}_{10}$ & $2.7(2.47-2.96)$ & $2.6(2.46-2.68)$ & $2.3(2.20-2.36)$ \\
$70 \mathrm{keV} / \mu \mathrm{m}$ & $\mathrm{D}_{37}$ & $1.5(1.13-1.74)$ & $1.4(1.21-1.49)$ & $1.1(1.02-1.25)$ \\
Iron ions & $\mathrm{D}_{10}$ & $2.4(2.33-2.49)$ & $2.1(1.99-2.23)$ & $2.1(1.97-2.24)$ \\
$200 \mathrm{keV} / \mu \mathrm{m}$ & $\mathrm{D}_{37}$ & $1.3(1.18-1.38)$ & $1.1(0.95-1.29)$ & $1.2(0.89-1.25)$ \\
\hline
\end{tabular}

$D_{10}$ and $D_{37}$ values were calculated from GraphPad Prism 5. Mean and 99\% confidence interval are shown. Experiments were carried out at least three times to obtain the data.

Comparison of BrdU substitution-induced radiosensitization effect with X-rays and heavy ions in a chromosomal aberration assay. As previously shown in the colony formation assay, BrdU-mediated radiosensitization was impaired as
LET increased (Fig. 1C and D). To further investigate the mechanism of cell killing, we analyzed first post-irradiation metaphase chromosomes with a chromosomal aberration assay. As predicted from the survival data, no additional 

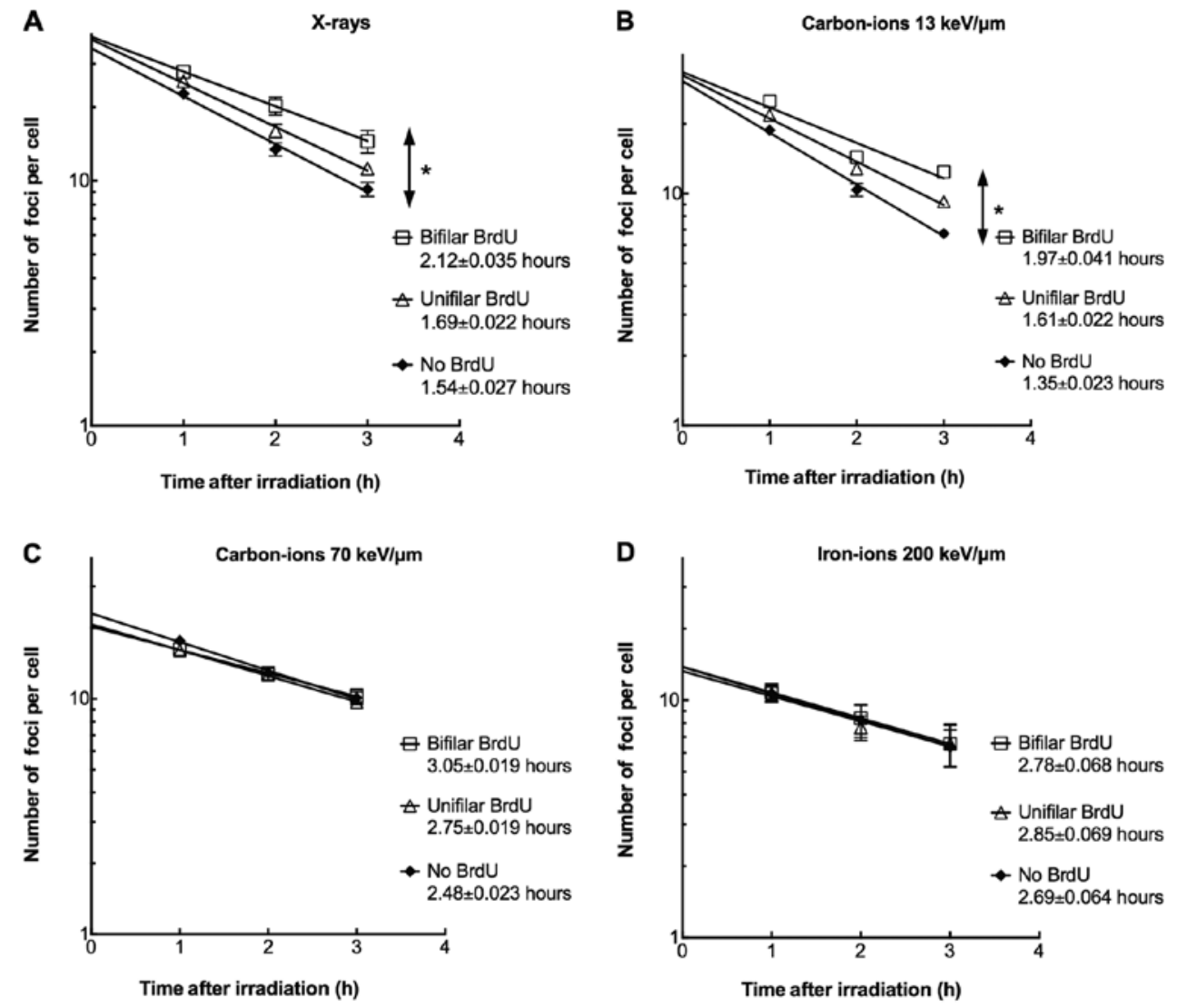

Figure 2. $\gamma$-H2AX focus formation assay. (A) X-rays, (B) LET $13 \mathrm{keV} / \mu \mathrm{m}$ carbon ions, (C) LET $70 \mathrm{keV} / \mu \mathrm{m}$ carbon ions, (D) LET $200 \mathrm{keV} / \mu \mathrm{m}$ iron ions. $\bullet$ No BrdU substitution; $\Delta$, unifilar substitution; $\square$, bifilar substitution. Half-life and standard error of the means are shown. Three to four independent experiments were carried out. Error bars indicate standard error of the means. Error bars smaller than symbols are not visible. ${ }^{*}$ Statistical significance $(\mathrm{P}<0.05, \mathrm{t}$-test $)$ between 0 and 1 cycle and between 0 and 2 cycles of BrdU incorporation.

Table II. Chromosomal aberration assay in first post-irradiation metaphase following irradiation at G1 phase with BrdU substitutions.

\begin{tabular}{lcccc}
\hline Radiation & Dose & No BrdU & Unifilar & Bifilar \\
\hline No irradiation & $0 \mathrm{~Gy}$ & $0.05 \pm 0.03$ & $0.11 \pm 0.05$ & $0.15 \pm 0.05$ \\
X-ray & $1 \mathrm{~Gy}$ & $0.30 \pm 0.03$ & $0.48 \pm 0.03$ & $0.71 \pm 0.04$ \\
& $2 \mathrm{~Gy}$ & $0.75 \pm 0.05$ & $1.01 \pm 0.06$ & $1.33 \pm 0.04$ \\
Carbon ions & $1 \mathrm{~Gy}$ & $0.42 \pm 0.05$ & $0.80 \pm 0.20$ & $1.00 \pm 0.00$ \\
$13 \mathrm{keV} / \mu \mathrm{m}$ & $2 \mathrm{~Gy}$ & $1.06 \pm 0.17$ & $1.56 \pm 0.24$ & $1.93 \pm 0.12$ \\
Carbon ions & $1 \mathrm{~Gy}$ & $1.26 \pm 0.13$ & $1.30 \pm 0.25$ & $1.23 \pm 0.09$ \\
$\quad 70 \mathrm{keV} / \mu \mathrm{m}$ & $2 \mathrm{~Gy}$ & $2.12 \pm 0.31$ & $2.54 \pm 0.69$ & $2.73 \pm 0.37$ \\
Iron ions & $1 \mathrm{~Gy}$ & $1.34 \pm 0.21$ & $1.26 \pm 0.26$ & $1.40 \pm 0.47$ \\
$200 \mathrm{keV} / \mu \mathrm{m}$ & $2 \mathrm{~Gy}$ & $2.84 \pm 0.13$ & $2.68 \pm 0.79$ & $2.70 \pm 0.64$ \\
\hline
\end{tabular}

More than 30 metaphase cells were scored in at least three independent experiments and calculated standard errors of mean.

chromosomal aberrations were observed after BrdU substitution and subsequent high-LET radiation exposure (Table II). After X-ray or LET $13 \mathrm{keV} / \mu \mathrm{m}$ carbon ion exposure, BrdU substitution-mediated radiosensitization was observed at each dose point (1 and $2 \mathrm{~Gy}$ ) with BrdU incorporation. For instance,

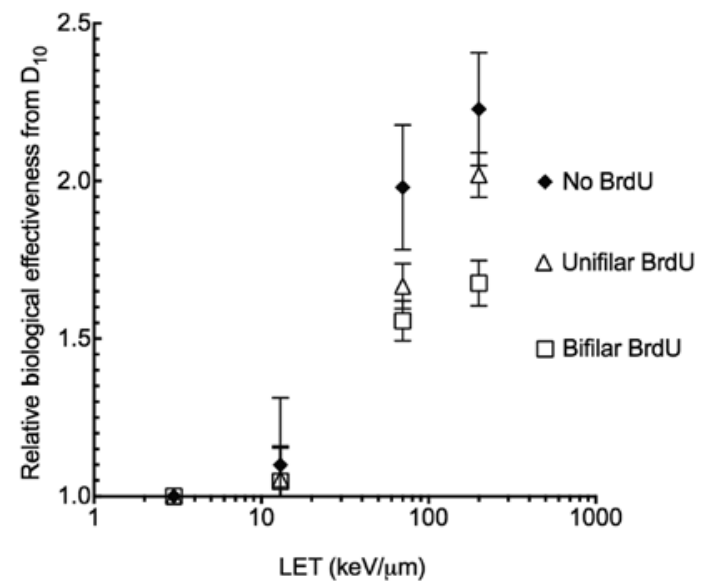

Figure 3. RBE values for different qualities of radiation. RBE values were calculated from the dose to achieve $10 \%$ survival. Error bars indicate standard errors of the means.

bifilar incorporation at 2 Gy increased chromosomal aberrations by 1.71 - (from 0.75 to 1.33 ) and 1.82-fold (from 1.06 to 1.93) for X-rays and LET $13 \mathrm{keV} / \mu \mathrm{m}$ carbon ions, respectively. In contrast, there was almost no radiosensitization at any dose or incorporation time as a result of carbon $(70 \mathrm{keV} / \mu \mathrm{m})$ or iron (200 keV/ $\mu \mathrm{m})$ ions. 

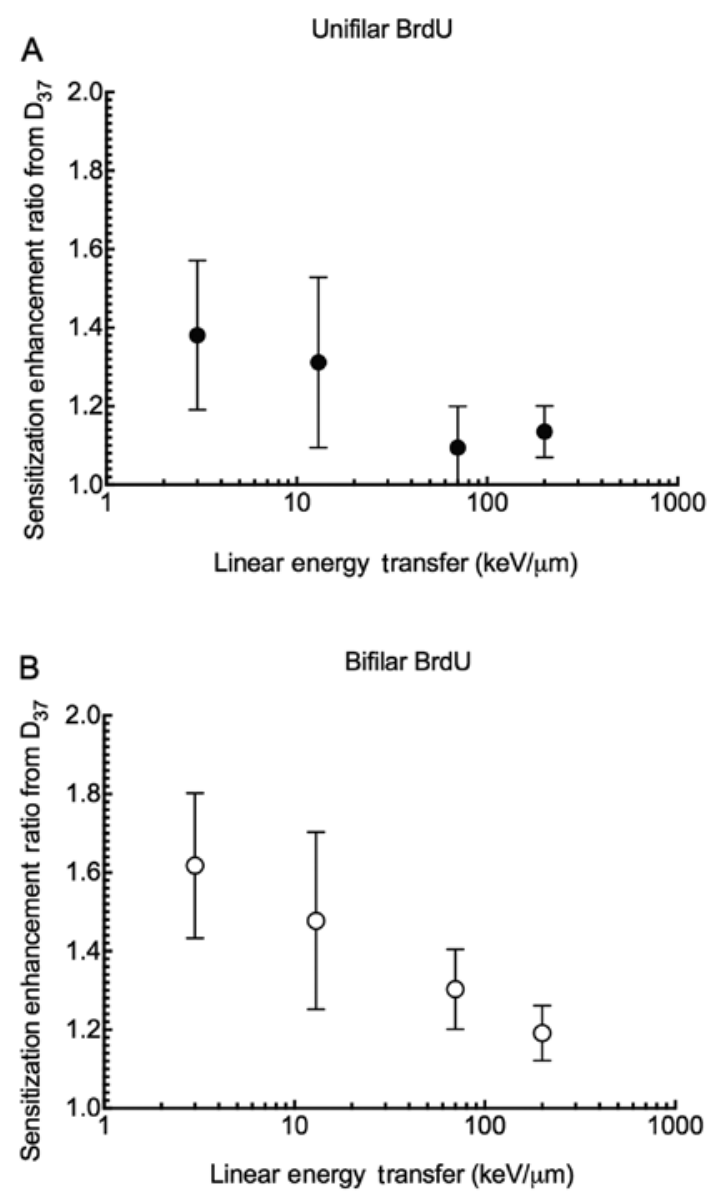

Figure 4. SER values for different qualities of radiation with unifilar (A) or bifilar (B) BrdU substitution. SER values were calculated from the dose to achieve $37 \%$ survival, which means the average of one lethal dose per population. Error bars indicate standard errors of the means.

Comparison of BrdU-induced enhancement effect with $X$-rays and heavy ions in the $\gamma-H 2 A X$ formation assay. DNA DSBs result in chromosomal aberrations and cell killing. To investigate the initial amount of DNA damage and DNA repair efficiency following various radiation exposures, we performed a $\gamma-\mathrm{H} 2 \mathrm{AX}$ foci formation assay. One hour after X-ray exposure 22.6 foci per cell for controls, 25.5 foci per cell for unifilar substitution (13\% increase), and 27.8 foci per cell for bifilar incorporation ( $23 \%$ increase) were scored. At $3 \mathrm{~h}$ after irradiation, the numbers of foci remaining were 9.2 for controls, 12.1 for unifilar incorporation (32\% increase), and 14.5 foci for bifilar incorporation (58\% increase) (Fig. 2). For LET $13 \mathrm{keV} / \mu \mathrm{m}$ carbon ions, the number of $\gamma-\mathrm{H} 2 \mathrm{AX}$ foci was 18.2 and 6.6 for controls, 21.5 (18\% increase) and 9.3 (41\% increase) for single BrdU incorporation, and 24.1 (52\% increase) and 12.1 (83\% increase) for double incorporation at 1 and $3 \mathrm{~h}$, respectively (Fig. 2). Low-LET radiation resulted in an increased number of initial BrdU-induced DNA DSBs and an increased amount of damage remaining in BrdU-incorporated cells. In contrast, high-LET radiation resulted in no significant difference in the number of initial BrdU-induced DNA DSBs or damage remaining in the BrdU-incorporated cells (Fig. 2).

To estimate the effects on repair capacity resulting from BrdU substitution, we calculated half-lives for the reduction of $\gamma$-H2AX foci between 1 and $3 \mathrm{~h}$ post-irradiation (Fig. 2).
Half lives for low-LET exposures increased with the amount of BrdU substitution (from 1.54 to $2.12 \mathrm{~h}$ for X-ray bifilar and 1.35 to $1.97 \mathrm{~h}$ for bifilar LET $13 \mathrm{keV} / \mu \mathrm{m}$ carbon-ions). In contrast, high-LET exposures (iron-ions in particular) showed no significant difference in $\gamma$-H2AX foci half-lives with or without BrdU substitution (from 2.69 to $2.78 \mathrm{~h}, \mathrm{P}<0.05$ ).

BrdU substitution effects RBE and SER. In order to assess BrdU substitution effects on radiosensitization, RBE and SER values were obtained. Without BrdU substitution, CHO10B2 cells showed a maximum of an $2.1 \mathrm{RBE}$ value at LET $200 \mathrm{keV} / \mu \mathrm{m}$. The LET values were decreased when cells were incorporated with unifilar or bifilar BrdU. The degree of reduction was stronger for bifilar BrdU substitution than unifilar BrdU substitution (Fig. 3). SER values showed that unifilar BrdU substitutions are 1.4 more effective in cell killing when compared to values without substitution with X-ray exposure, while there was only a 1.1 increase in effectiveness with high LET radiation such as carbon $70 \mathrm{keV} / \mu \mathrm{m}$ and iron ions $200 \mathrm{keV} / \mu \mathrm{m}$ (Fig. 4). The same trend was observed for bifilar substitution. The SER values were decreased from 1.6 to 1.2.

\section{Discussion}

In order to investigate the reduced synergistic effects of a combination of high-LET radiation and BrdU incorporation, we compared the damage resulting from low- or high-LET radiation exposure with and without BrdU substitution with several endpoints. We showed that BrdU substitution mediated radiosensitization effects on low-LET photon radiation and particle radiation but similar cellular lethality was observed after high-LET radiation (Fig. 1). Linstadt et al (25) proved that the extent of radiosensitization caused by IdU, a halogenated pyrimidine, decreased as the LET increased. In addition, they found very small sensitization enhancements for the distal peak $(82 \mathrm{keV} / \mu \mathrm{m})$ and Bragg peak $(183 \mathrm{keV} / \mu \mathrm{m})$ of a Neon ion beam and no radiosensitization was observed for an extremely high-LET Lanthanum ion beam with $1000 \mathrm{keV} / \mu \mathrm{m} \mathrm{(25).} \mathrm{Our}$ study was consistent with these results as carbon ions with LET $70 \mathrm{keV} / \mu \mathrm{m}$ and iron ions with LET $200 \mathrm{keV} / \mu \mathrm{m}$ following unifilar or bifilar BrdU incorporation yielded very weak radiosensitization for cellular lethality. Fig. 3 shows the RBE values calculated from $\mathrm{D}_{10}$ with BrdU substitution (Table I). Smaller RBE values were noted after high-LET radiation exposure with BrdU substitution. Among the same BrdU substituted cells, high-LET and high RBE advantage was lost. The SER values for high-LET were smaller when cells were incorporated with more BrdU (Fig. 4A and B). When halogenated pyrimidine is used for clinical practice, it is worthy to note that enhancement of cell killing would be smaller using carbon ion radiotherapy than that expected in X-ray radiotherapy. Normal tissues incorporated with BrdU would be severely sensitized following low-LET exposure. Therefore, the dose to patients should be reduced to avoid adverse side effects.

Fig. 2 shows that initial (1 h post-irradiation) DNA damage observed as phosphorylated $\mathrm{H} 2 \mathrm{AX}$ foci was increased with BrdU incorporation degrees only for low-LET radiation but not high-LET radiation. Therefore, we assume that initial DNA damages are increased with BrdU substitution for low-LET radiation but not for high-LET radiation. This result was 
consistent with other reports $(4,15)$. As a result of more initial damage and slower repair, there were additional $\gamma$-H2AX foci in BrdU substituted cells after low-LET radiation. $\gamma$-H2AX foci are excellent markers for DNA double-strand breaks. H2AX is phosphorylated 2 mega bases from a DSB site $(35,36)$. We could not exclude the possibility that additional DSBs were produced by BrdU sensitization following high-LET radiation within short range to be recognized as a single focus.

In order to evaluate DNA repair kinetics, we calculated the half-life of $\gamma$-H2AX foci from 1 to $3 \mathrm{~h}$ after irradiation (Fig. 2). Many DNA DSB repair deficient mutants were found to have slower kinetics of DSB repair and $\gamma-\mathrm{H} 2 \mathrm{AX}$ foci disappearance (37-39). Half-lives of $\gamma-\mathrm{H} 2 \mathrm{AX}$ foci were affected by BrdU substitutions for low-LET radiation, but not for highLET radiation (Fig. 2). The results coincide with other studies, suggesting that slower repair is one of the possible mechanisms for BrdU-induced radiosensitization $(2,13,16,40)$. In contrast, one study found that halogenated pyrimidines did not effect the repair of PLD for low-LET radiation (X-rays and neon ions with LET $38 \mathrm{keV} / \mu \mathrm{m}$ ) and sublethal damage repair (25).

We clearly observed that the combination of BrdU and high-LET radiation does not increase the half-life of $\gamma$-H2AX foci disappearance any more than high-LET radiation alone. This suggests that the BrdU substitution did not modify DNA DSBs produced by high-LET radiation or such modifications were naturally formed by high-LET radiation. Multiple publications suggest that high-LET radiation produces dense ionization in their tracks and produce multiple damages near DNA double-strand breaks and form clustered and complex damage $(4,12,22,41)$. These damages are very difficult to repair and it results in high lethality per absorbed physical dose. BrdU-mediated free radicals form lesions such as single-strand breaks, double-strand breaks, and complex double-strand breaks (12). We assumed that BrdU could not contribute any biological response once high-LET produced enough dense ionization on their target. LET $>100 \mathrm{keV} / \mu \mathrm{m}$ constitutes an overdose as excess ionizing events do not efficiently produce DSBs (41-43).

These results indicate that there was no detectable difference in the amount of DNA double-strand break formation and no detectable effects for repair kinetics for high-LET radiation with or without BrdU incorporation. These results were directly correlated to no differences in the frequency of chromosomal aberrations in metaphase chromosomes and cellular lethality for high LET radiation with or without BrdU substitution (Fig. 1, Table II).

BrdU and other halogenated pyrimidines appear not to be practical sensitizers to combine with carbon ion radiotherapy due to the severe sensitization to normal tissue and the small sensitization to cancer at higher LET radiation. But LET for the spread out Bragg peak for carbon ion radiotherapy contains a wide range of LET $(32,34,44)$. In this range we would expect some sensitization for tumor control but the SER would not be as high as that for low-LET radiation such as photon and proton radiation.

\section{Acknowledgments}

We thank Dr Jamie Bush and Mr. Charles Yurkon of Colorado State University for proofreading our manuscript. This study was partially supported by the Japan Society for the Promotion of Science Grant in Aid (Young Scientists B19710056 to T.K.) and by start-up funds from Colorado State University and Dr Akiko M. Ueno Radiation Biology Research Fund. This study was part of a Research Project with Heavy Ions at the NIRS (National Institute of Radiological Sciences)-HIMAC.

\section{References}

1. Mitchell JB, Russo A, Cook JA, Straus KL and Glatstein E: Radiobiology and clinical application of halogenated pyrimidine radiosensitizers. Int J Radiat Biol 56: 827-836, 1989.

2. Franken NA, Van Bree CV, Kipp JB and Barendsen GW: Modification of potentially lethal damage in irradiated Chinese hamster V79 cells after incorporation of halogenated pyrimidines. Int J Radiat Biol 72: 101-109, 1997.

3. McLaughlin PW, Lawrence TS, Seabury H, et al: Bromodeoxyuridine-mediated radiosensitization in human glioma: the effect of concentration, duration, and fluoropyrimidine modulation. Int J Radiat Oncol Biol Phys 30: 601-607, 1994.

4. Kinsella TJ, Dobson PP, Mitchell JB and Fornace AJ Jr: Enhancement of X ray-induced DNA damage by pre-treatment with halogenated pyrimidine analogs. Int J Radiat Oncol Biol Phys 13: 733-739, 1987.

5. Zeng Y and Wang Y: UVB-induced formation of intrastrand cross-link products of DNA in MCF-7 cells treated with 5-bromo-2'-deoxyuridine. Biochemistry 46: 8189-8195, 2007.

6. Zeng Y and Wang Y: Sequence-dependent formation of intrastrand crosslink products from the UVB irradiation of duplex DNA containing a 5-bromo-2'-deoxyuridine or 5-bromo-2'-deoxycytidine. Nucleic Acids Res 34: 6521-6529, 2006.

7. Puck TT and Kao FT: Genetics of somatic mammalian cells. V. Treatment with 5-bromodeoxyuridine and visible light for isolation of nutritionally deficient mutants. Proc Natl Acad Sci USA 58: 1227-1234, 1967.

8. Iliakis G, Pantelias G and Kurtzman S: Mechanism of radiosensitization by halogenated pyrimidines: effect of BrdU on cell killing and interphase chromosome breakage in radiationsensitive cells. Radiat Res 125: 56-64, 1991

9. Webb CF, Jones GD, Ward JF, Moyer DJ, Aguilera JA and Ling LL: Mechanisms of radiosensitization in bromodeoxyuridine-substituted cells. Int J Radiat Biol 64: 695-705, 1993.

10. Zimbrick JD, Ward JF and Myers LS Jr: Studies on the chemical basis of cellular radiosensitization by 5-bromouracil substitution in DNA. I. Pulse- and steady-state radiolysis of 5-bromouracil and thymine. Int J Radiat Biol Relat Stud Phys Chem Med 16: 505-523, 1969.

11. Zimbrick JD, Ward JF and Myers LS Jr: Studies on the chemical basis of cellular radiosensitization by 5-bromouracil substitution in DNA. II. Pulse- and steady state radiolysis of bromouracilsubstituted and -unsubstituted DNA. Int J Radiat Biol Relat Stud Phys Chem Med 16: 525-534, 1969.

12. Watanabe $\mathrm{R}$ and Nikjoo $\mathrm{H}$ : Modelling the effect of incorporated halogenated pyrimidine on radiation-induced DNA strand breaks. Int J Radiat Biol 78: 953-966, 2002.

13. Jones GD, Ward JF, Limoli CL, Moyer DJ and Aguilera JA: Mechanisms of radiosensitization in iododeoxyuridine-substituted cells. Int J Radiat Biol 67: 647-653, 1995.

14. Iliakis G, Wang Y, Pantelias GE and Metzger L: Mechanism of radiosensitization by halogenated pyrimidines: effect of BrdU on repair of DNA breaks, interphase chromatin breaks, and potentially lethal damage in plateau-phase CHO cells. Radiat Res 129: 202-211, 1992.

15. Iliakis G, Kurtzman S, Pantelias G and Okayasu R: Mechanism of radiosensitization by halogenated pyrimidines: effect of BrdU on radiation induction of DNA and chromosome damage and its correlation with cell killing. Radiat Res 119: 286-304, 1989.

16. Iliakis $G$ and Kurtzman S: Mechanism of radiosensitization by halogenated pyrimidines: bromodeoxyuridine and beta-arabinofuranosyladenine affect similar subsets of radiation-induced potentially lethal lesions in plateau-phase Chinese hamster ovary cells. Radiat Res 127: 45-51, 1991.

17. Blakely EA and Kronenberg A: Heavy-ion radiobiology: new approaches to delineate mechanisms underlying enhanced biological effectiveness. Radiat Res 150: S126-S145, 1998.

18. Eguchi-Kasai K, Murakami M, Itsukaichi H, et al: Repair of DNA double-strand breaks and cell killing by charged particles. Adv Space Res 22: 543-549, 1998. 
19. Tsujii H, Mizoe JE, Kamada T, et al: Overview of clinical experiences on carbon ion radiotherapy at NIRS. Radiother Oncol 73 (Suppl 2): S41-S49, 2004.

20. Jakel O: The relative biological effectiveness of proton and ion beams. Z Med Phys 18: 276-285, 2008.

21. Prise KM, Pinto M, Newman HC and Michael BD: A review of studies of ionizing radiation-induced double-strand break clustering. Radiat Res 156: 572-576, 2001.

22. Fakir H, Sachs RK, Stenerlow B and Hofmann W: Clusters of DNA double-strand breaks induced by different doses of nitrogen ions for various LETs: experimental measurements and theoretical analyses. Radiat Res 166: 917-927, 2006.

23. Hada M and Georgakilas AG: Formation of clustered DNA damage after high-LET irradiation: a review. J Radiat Res 49: 203-210, 2008

24. Pinto M, Prise KM and Michael BD: Evidence for complexity at the nanometer scale of radiation-induced DNA DSBs as a determinant of rejoining kinetics. Radiat Res 164: 73-85, 2005.

25. Linstadt D, Blakely E, Phillips TL and Castro JR: Radiosensitization produced by iododeoxyuridine with high linear energy transfer heavy ion beams. Int J Radiat Oncol Biol Phys 15: 703-710, 1988

26. Oliveira NG, Castro M, Rodrigues AS, et al: Wortmannin enhances the induction of micronuclei by low and high LET radiation. Mutagenesis 18: 37-44, 2003.

27. Skarsgard LD: Radiobiology with heavy charged particles: a historical review. Phys Med 14 (Suppl 1): 1-19, 1998.

28. Hamada N, Imaoka T, Masunaga S, et al: Recent advances in the biology of heavy-ion cancer therapy. J Radiat Res 51: 365-383, 2010.

29. Nagasawa $\mathrm{H}$ and Little JB: Effect of tumor promoters, protease inhibitors, and repair processes on X-ray-induced sister chromatid exchanges in mouse cells. Proc Natl Acad Sci USA 76: 1943-1947, 1979

30. Terasima T and Tolmach LJ: Changes in X-ray sensitivity of HeLa cells during the division cycle. Nature 190: 1210-1211, 1961.

31. Kanai T, Endo M, Minohara S, et al: Biophysical characteristics of HIMAC clinical irradiation system for heavy-ion radiation therapy. Int J Radiat Oncol Biol Phys 44: 201-210, 1999.

32. Kanai T, Matsufuji N, Miyamoto T, et al: Examination of GyE system for HIMAC carbon therapy. Int J Radiat Oncol Biol Phys 64: 650-656, 2006.

33. Matsufuji N, Fukumura A, Komori M, Kanai T and Kohno T: Influence of fragment reaction of relativistic heavy charged particles on heavy-ion radiotherapy. Phys Med Biol 48: 1605-1623, 2003.
34. Matsufuji N, Kanai T, Kanematsu N, et al: Specification of carbon ion dose at the National Institute of Radiological Sciences (NIRS). J Radiat Res 48 (Suppl A): A81-A86, 2007.

35. Rogakou EP, Boon C, Redon C and Bonner WM: Megabase chromatin domains involved in DNA double-strand breaks in vivo. J Cell Biol 146: 905-915, 1999.

36. Rogakou EP, Boon C and Bonner WM: Formation of a nove histone derivative, $\mathrm{H} 2 \mathrm{AX}$ phosphorylated on serine-139, is an immediate cellular response to non-lethal and lethal amounts of ionizing radiation, and is also found during apoptosis and in germ cells. Mol Biol Cell 8: 1858-1858, 1997.

37. Banath JP, MacPhail SH and Olive PL: Radiation sensitivity, $\mathrm{H} 2 \mathrm{AX}$ phosphorylation, and kinetics of repair of DNA strand breaks in irradiated cervical cancer cell lines. Cancer Res 64: 7144-7149, 2004.

38. Kuhne M, Riballo E, Rief N, Rothkamm K, Jeggo PA and Lobrich M: A double-strand break repair defect in ATM-deficient cells contributes to radiosensitivity. Cancer Res 64: 500-508, 2004.

39. Kato TA, Nagasawa H, Weil MM, Little JB and Bedford JS: Levels of gamma-H2AX foci after low-dose-rate irradiation reveal a DNA DSB rejoining defect in cells from human ATM heterozygotes in two at families and in another apparently normal individual. Radiat Res 166: 443-453, 2006.

40. Wang Y, Pantelias GE and Iliakis G: Mechanism of radiosensitization by halogenated pyrimidines: the contribution of excess DNA and chromosome damage in BrdU radiosensitization may be minimal in plateau-phase cells. Int J Radiat Biol 66: 133-142, 1994.

41. Prise KM, Folkard M, Newman HC and Michael BD: Effect of radiation quality on lesion complexity in cellular DNA. Int J Radiat Biol 66: 537-542, 1994.

42. Chapman JD, Doern SD, Reuvers AP, et al: Radioprotection by DMSO of mammalian cells exposed to X-rays and to heavy charged-particle beams. Radiat Environ Biophys 16: 29-41, 1979.

43. Yang TC, Craise LM, Mei MT and Tobias CA: Neoplastic cell transformation by heavy charged particles. Radiat Res Suppl 8: S177-S187, 1985

44. Fukumura A, Tsujii H, Kamada T, et al: Carbon-ion radiotherapy: clinical aspects and related dosimetry. Radiat Prot Dosimetry 137: 149-155, 2009. 